Jurnal Sulolipu : Media Komunikasi Sivitas Akademika dan Masyarakat

Vol. 19 No.2 2019

e-issn : 2622-6960, p-issn : 0854-624X

\title{
FAKTOR YANG BERHUBUNGAN DENGAN GANGGUAN KESEHATAN KERJA PADA KARYAWAN BAGIAN PRODUKSI DI PT. SEMEN TONASA KABUPATEN PANGKEP \\ Nurul Dwi Ilmiah Ningrum ${ }^{1}$, Juherah ${ }^{2}$ \\ 1,2, Jurusan Kesehatan Lingkungan Poltekkes Kemenkes Makassar \\ nurulndin9@gmail.com / 081224855379
}

\begin{abstract}
Health problems or occupational diseases are artificial or man made disease. This is a problem for workers in various sectors. This study aims to determine the factors associated with occupational health problems in employees of the production section II, III and IV at PT. Semen Tonasa Pangkep Year 2019. This type of research was observational analytic using a cross sectional study design with a sampling technique using simple random sampling of 102 employees in the production section. Data analysis carried out was univariate and bivariate with chi-square test. The results of the study using the chi square test there is a relationship between health problems with health and safety counseling, namely ( $p=0.029)$, there is no relationship between health problems with Personal Protective Equipment (PPE), namely ( $p=0.227)$, there is a relationship between health problems with workload that is $(p=0.00)$ and there is a relationship between health problems with fatigue that is $(p=0.00)$. The conclusion of the study is that there is a relationship between health and safety counseling, workload and work fatigue with health problems but there is no relationship between the use of personal protective equipment and health problems. Researchers suggest that the company PT. Semen Tonasa, Pangkep Regency, especially in the production sector, is to increase counseling to factory employees.
\end{abstract}

Keywords: K3 Counseling, Personal Protective Equipment (PPE), Workload, Fatigue with Health Problems.

ABSTRAK

Gangguan kesehatan atau penyakit akibat kerja merupakan penyakit yang arti fisial atau man made disease. Hal ini merupakan problem bagi para pekerja di berbagai sektor. Penelitian ini bertujuan untuk mengetahui faktor yang berhubungan dengan gangguan kesehatan kerja pada karyawan bagian produksi II, III dan IV di PT. Semen Tonasa Pangkep Tahun 2019. Jenis penelitian ini adalah observasional analitik menggunakan rancangan penelitian cross sectional dengan teknik pengambilan sampel menggunakan simple random sampling sebanyak 102 karyawan di bagian produksi. Analisis data yang dilakukan adalah univariat dan bivariat dengan uji chi-square. Hasil penelitian dengan menggunakan uji chi square ada hubungan antara gangguan kesehatan dengan penyuluhan kesehatan dan keselamatan kerja yaitu $(p=0.029)$, tidak ada hubungan antara gangguan kesehatan dengan Alat Pelindung Diri (APD) yaitu $(p=0,227)$, ada hubungan antara gangguan kesehatan dengan beban kerja yaitu $(p=0,00)$ dan ada hubungan antara gangguan kesehatan dengan kelelahan yaitu $(p=0,00)$. Kesimpulan penelitian adalah ada hubungan antara penyuluhan kesehatan dan keselamatan kerja, beban kerja dan kelelahan kerja dengan gangguan kesehatan tapi tidak ada hubungan antara penggunaan alat pelindung diri dengan gangguan kesehatan. Peneliti menyarankan bagi pihak perusahaan PT. Semen Tonasa Kabupaten Pangkep khususnya di bagian produksi agar meningkatkan penyuluhan terhadap karyawan pabrik.

Kata Kunci : Penyuluhan K3, Alat Pelindung Diri (APD), Beban Kerja, Kelelahan Kerja dengan Gangguan Kesehatan

\section{PENDAHULUAN}

PT. Semen Tonasa merupakan salah satu industri yang bergerak sebagai produsen semen terbesar di Kawasan Timur Indonesia yang menempati lahan seluas 715 hektar di Desa Biringere, Kecamatan Bungoro, Kabupaten Pangkep, sekitar 68 kilometer dari kota Makassar. Perseroan yang memiliki kapasitas terpasang 5.980 .000 ton semen tahun ini mempunyai IV unit pabrik yaitu: Pabrik Tonasa II, III, IV dan V (PT. Semen Tonasa, 2017). Adapun yang mendasari peneliti memilih PT. Semen Tonasa sebagai tempat penelitian karena berdasarkan hasil observasi awal kondisi lingkungan PT. Semen Tonasa yaitu didapatkan pencemaran polusi udara dalam bentuk emisi gas karbon maupun partikel-partikel (debu) dan berdasarkan data laporan triwulan pemantauan kesehatan kerja tahun 2017 yang di dapatkan di PT. Semen Tonasa yaitu $69(24 \%)$ orang sakit akibat gangguan kesehatan kerja. Sebagai tindak lanjut kondisi diatas maka penulis tertarik untuk meneliti tentang Faktor Yang Berhubungan Dengan Gangguan Kesehatan Kerja Pada Karyawan Bagian Produksi II, III dan IV di PT. Semen Tonasa Kabupaten Pangkep khususnya pada Penyuluhan K3, penggunaan alat pelindung diri (APD), beban kerja dan kelelahan kerja.

\section{METODE}

Metode yang digunakan dalam penelitian ini yaitu rancangan penelitian cross sectional. Dengan tujuan untuk mengetahui apakah penyuluhan K3, penggunaan APD, beban kerja dan kelelahan kerja menjadi faktor risiko adanya pengaruh gangguan kesehatan kerja pada karyawan bagian produksi di PT. Semen Tonasa Kabupaten Pangkep.

\section{Desain, tempat dan waktu}

Jenis penelitian yang digunakan observasional analitik dengan pendekatan croos sectional dengan tujuan untuk 
mengetahui apakah penyuluhan $\mathrm{K} 3$, penggunaan APD, beban kerja dan kelelahan kerja menjadi faktor risiko adanya pengaruh gangguan kesehatan kerja pada karyawan bagian produksi di PT. Semen Tonasa Kabupaten Pangkep.

Adapun pelaksanaan penelitian dilakukan pada 2 tahap yaitu tahap persiapan, meliputi kegiatan seminar proposal yang dilaksanakan pada Bulan Desember 2018Januari 2019. Tahap kedua pelaksanaan meliputi pengumpulan data yang kemudian ujian hasil yang dilaksanakan pada bulan april-juni 2019.

\section{Jumlah dan cara pengambilan subjek}

Teknik pengambilan sampel yang digunakan yaitu random sampel. Adapun sampel yang diteliti yaitu sebanyak 55 karyawan pada produksi IV dan 78 karyawan pada produksi II, III total keseluruhan yaitu 133 karyawan.

Cara pengambilan sampel ditentukan dengan menggunakan rumus sebagai berikut : Rumus Slovin (1960) : $\mathrm{n} \frac{N}{1+N(d)^{2}}$

Dimana :

$\mathrm{n}$ = besarnya sampel

$\mathrm{N}$ = besarnya populasi

$\mathrm{d}=$ Tingkat kepercayaan atau ketetapan $(0,05)$

$$
\begin{aligned}
n & =\frac{133}{1+133(0,05)^{2}} \\
& =\frac{133}{1+133 \times 0,0025} \\
& =\frac{133}{1,3} \\
& =102 \text { karyawan. }
\end{aligned}
$$

\section{Jenis dan Cara Pengumpulan Data (untuk penelitian survei) / Langkah-Langkah Penelitian}

a. Data primer

Data primer diperoleh pada bagian produksi II,III dan IV di PT. Semen Tonasa melalui observasi, wawancara pada responden dengan menggunakan alat ukur berupa lembar kuesioner berskala Guttman, data yang diperoleh berupa data interval atau rasio dikotomi (dua alternatif) yaitu 'Ya' dan 'Tidak' sehingga dengan demikian peneliti berharap mendapatkan jawaban yang tegas terhadap suatu permasalahan yang akan diteliti.

b. Data sekunder

Data yang diperoleh dengan mengumpulkan data yang bersumber dari literatur-literatur, bahan kuliah, buku-buku dan hasil penelitian lainnya

\section{Pengolahan dan analisis data}

Analisis data ditentukan untuk mengetahui hubungan antara variabel bebas dan variable terikat. Selain itu, analisis data dapat digunakan untuk menguji hipotesa penelitian. Dalam penelitian ini menggunakan teknik :

a. Analisis satu variable (univariate) Analisis univarite dilakukan untuk mendeskripsikan variabel bebas yaitu meliputi penyuluhan K3, Penggunaan APD, beban kerja dan kelelahan kerja.

b. Analisis dua variabel (bivariate) Analisis bivariate dilakukan terhadap dua variable yang diduga berhubungan. Analisis ini menggunakan uji statistic berupa uji chi square guna mengetahui faktor yang berhubungan antara gangguan kesehatan kerja pada karyawan bagian produksi di PT. Semen Tonasa Kabupaten Pangkep.

Dengan rumus sebgai berikut:

$$
x^{2}=\sum \frac{(O-E)^{2}}{E}
$$

Keterangan:

$\mathrm{X}^{2}$ : Chi Square

$\mathrm{O}$ : Nilai Observasi (pengamatan)

E : Nilai Expected (harapan).

\section{HASIL}

Adapun hasil dari penelitian ini yaitu :

a. Hubungan penyuluhan $\mathrm{K} 3$ dengan gangguan kesehatan kerja

Berdasarkan tabel 5.6 hasil yang diperoleh bahwa dari 102 karyawan/buruh yang pernah mendapatkan penyuluhan K3 terdapat $85(83 \%)$ dan yang tidak pernah mendapatkan penyuluhan K3 terdapat 17 (17\%). Sedangkan yang pernah mengalami gangguan kesehatan yaitu 63 (62\%) dan tidak pernah mengalami gangguan kesehatan yaitu 39 (38\%) karyawan/buruh di pabrik II, III dan IV. Berdasarkan hasil uji statistik dengan menggunakan uji chi square diperoleh nilai $p$ value $0,029<\alpha(0,05)$ maka Ho ditolak dan nilai $\mathrm{Ha}$ diterima dengan 
kesimpulan bahwa ada hubungan yang bermakna antara penyuluhan K3 dengan gangguan kesehatan kerja hal ini disebabkan karena sebagian besar pekerja pernah mendapatkan penyuluhan K3 tapi tidak menerapkan sepenuhnya pengetahuan yang didapatkan.

b. Hubungan penggunaan alat pelindung dir (APD) dengan gangguan kesehatan kerja. Berdasarkan 5.7 hasil yang telah di peroleh bahwa dari 102 karyawan/buruh yang menggunakan alat pelindung diri yaitu 90 (88\%) dan yang tidak menggunakan alat pelindung diri yaitu 12 (12\%). Sedangkan yang pernah mengalami gangguan kesehatan yaitu 63 $(62 \%)$ dan tidak pernah mengalami gangguan kesehatan yaitu 39 (38\%) karyawan/buruh di pabrik II, III dan IV. Berdasarkan hasil uji statistik dengan menggunakan uji chi square diperoleh nilai nilai $p$ value $0,204>\alpha(0,05)$ maka $\mathrm{Ha}$ ditolak dan nilai Ho diterima dengan kesimpulan bahwa tidak ada hubungan yang bermakna antara penggunaan alat pelindung diri (APD) dengan gangguan kesehatan kerja hal ini disebabkan karena sebagian besar karyawan/buruh yang berada di lokasi menggunakaan APD seperti helm, masker, pelindung mata dan sepatu safety sehingga dapat mengurangi resiko terjadinya gangguan kesehatan.

c. Hubungan beban kerja dengan gangguan kesehatan kerja.

Berdasarkan tabel 5.8 hasil yang telah di peroleh bahwa dari 102 karyawan/buruh yang mengalami beban kerja yaitu 79 (77\%) dan yang tidak mengalami beban kerja yaitu 23 (23\%). Sedangkan yang pernah mengalami gangguan kesehatan yaitu 63 (62\%) dan tidak pernah mengalami gangguan kesehatan yaitu 39 (39\%) karyawan/buruh di pabrik II, III dan IV. Berdasarkan hasil uji statistik dengan menggunakan uji chi square diperoleh nilai $p$ value $0,000<\alpha \quad(0,05)$ maka Ho ditolak dan nilai Haditerima dengan kesimpulan bahwa ada hubungan yang bermakna antara beban kerja dengan gangguan kesehatan kerja.

d. Hubungan kelelahan kerja dengan gangguan kesehatan kerja.

Berdasarkan tabel 5.9 hasil yang telah di peroleh bahwa dari 102 karyawan/buruh yang mengalami kelelahan yaitu 64 (63\%) dan yang tidak mengalami kelelahan yaitu 38 (37\%). Sedangkan yang pernah mengalami gangguan kesehatan yaitu 63 $(62 \%)$ dan tidak pernah mengalami gangguan kesehatan yaitu 39 (38\%) karyawan/buruh di pabrik II, III dan IV. Berdasarkan hasil uji statistik dengan menggunakan uji chi square diperoleh nilai $p$ value $0,000<\alpha \quad(0,05)$ maka Ho ditolak dan nilai $\mathrm{Ha}$ diterima dengan kesimpulan bahwa ada hubungan yang bermakna antara kelelahan kerja dengan gangguan kesehatan kerjahal ini disebabkan karena sebagian besar kayawan merasakan lelah dalam melakukan pekerjaan.

Distribusi Responden berdasarkan Gangguan Kesehatan karyawan/buruh pabrik II,III dan IV di PT. Semen Tonasa Kabupaten Pangkep.

\begin{tabular}{lll}
$\begin{array}{l}\text { Gangguan } \\
\text { Kesehatan }\end{array}$ & Jumlah & Persentase \\
\hline Pernah & 63 & $62 \%$ \\
Tidak & 39 & $38 \%$ \\
Pernah & & \\
Jumlah & 102 & $100 \%$ \\
\hline
\end{tabular}

Sumber : Data Primer 2019

Distribusi Responden berdasarkan penyuluhan K3 karyawan/buruh pabrik II,III dan IV di PT. Semen Tonasa Kabupaten Pangkep.

\begin{tabular}{lcc}
\hline $\begin{array}{c}\text { Penyuluhan } \\
\text { K3 }\end{array}$ & Jumlah & Persentase \\
\hline Pernah & 85 & $83 \%$ \\
\hline Tidak & 17 & $17 \%$ \\
Pernah & 102 & $\mathbf{1 0 0} \%$ \\
\hline Jumlah & $\mathbf{1 0 2}$
\end{tabular}

Sumber : Data Primer 2019

Distribusi Responden berdasarkan Penggunaan Alat Pelindung Diri (APD) karyawan/buruh pabrik II,III dan IV di PT. Semen Tonasa Kabupaten Pangkep.

Penggunaan Jumlah Persentase
Alat

Pelindung

Diri (APD)

\begin{tabular}{lcc} 
Menggunakan & 90 & $88 \%$ \\
\hline Tidak & 12 & $12 \%$ \\
Menggunakan & & \\
\hline Jumlah & $\mathbf{1 0 2}$ & $\mathbf{1 0 0 \%}$
\end{tabular}

Sumber : Data Primer 2019 
Distribusi Responden berdasarkan Beban Kerja karyawan/buruh pabrik II,III dan IV di PT. Semen Tonasa Kabupaten Pangkep.

\begin{tabular}{lll}
\hline $\begin{array}{l}\text { Beban } \\
\text { Kerja }\end{array}$ & JUMLAH PERSENTASE \\
\hline
\end{tabular}

\begin{tabular}{lll}
\hline Memenuhi & 79 & $77 \%$ \\
\hline Tidak & 23 & $23 \%$
\end{tabular}

Memenuhi

\begin{tabular}{lll}
\hline JUMLAH & 102 & $100 \%$
\end{tabular}

Sumber : Data Primer 2019

\section{PEMBAHASAN}

Berdasarkan hasil penelitian dan analisa data yang telah dilakukan di pabrik produksi Tonasa II, III dan IV diketahui bahwa:

1. Hubungan penyuluhan $\mathrm{K} 3$ dengan gangguan kesehatan kerja

Berdasarkan hasil wawancara yang dilakukan ada beberapa karyawan/buruh yang sama sekali tidak pernah mendapatkan penyuluhan K3 dengan alasan dari pihak kantormemilih-milih karyawan/buruh yang dipanggil untuk melakukan atau menghadiri penyuluhan K3, tetapi karyawan yang telah mendapatkan penyuluhan memberikan informasi kepada karyawan/buruh yang tidak mengikuti penyuluhan K3 sehingga mereka mengetahui apa itu penyuluhan K3 meskipun tidak mengikuti langsung penyulahan K3.

2. Hubungan penggunaan alat pelindung diri (APD) dengan gangguan kesehatan kerja Alat Pelindung Diri (APD) adalah peralatan keselamatan yang harus digunakan oleh personel apabila berada pada suatu tempat kerja yang berbahaya. Berdasarkan hasil observasi langsung yang dilakukan selama penelitian masih ada karyawan yang bekerja tidak menggunakan APD sesuai dengan risiko kerja. Demi menghindari kecelakaan kerja petugas safety memasang sedemikian rupa rambu-rambu K3 berupa wajib menggunakan APD pada bagian-bagian tertentu, misalnya pada bagian raw mill yang diwajibkan menggunakan ear plug tapi ada beberapa karyawan yang bekerja pada bagian raw mill tidak menggunakan ear plug dan pada bagian packer para karyawan/buruh diwajibkan menggunakan maskertapi ada saja karyawan/buruh yang tidak menggunakan masker. Berdasarkan hasil penelitian yang dilakukan pada karyawan/buruh mengenai mengapa tidak menggunakan ear plug pada saat dilokasi pabrik khususnya di bagian raw mill, karyawan/buruh mengatakan mereka tidak nyaman menggunakan ear plug sehingga mereka tidak memakai ear plug pada saat bekerja. Disamping itu ternyata dari pihak K3 ear plug yang mereka sediakan tidak memenuhi sehingga ada karyawan/buruh tidak kebagian.

3. Hubungan beban kerja dengan gangguan kesehatan kerja

Beban kerja adalah kemampuan tubuh pekerja dalam menerima pekerjaan. Dari sudut pandang ergonomi, setiap beban kerja yang diterima seseorang harus sesuai dan seimbang terhadap kemampuan fisik maupun psikologis pekerja yang menerima beban kerja tersebut. Berdasarkan tabel 5.8 hasil analisis bivariat dengan menggunakan uji chi square diperoleh nilai $p$ value 0,000 $<\alpha \quad(0,05)$ maka Ho ditolak dan nilai Haditerima dengan kesimpulan bahwa ada hubungan yang bermakna antara beban kerja dengan gangguan kesehatan kerja.

$\mathrm{Hal}$ ini disebabkan karena berdasarkan hasil penelitian yang dilakukan menggunakan kuesioner pada karyawan/buruh mengenai beban kerja, sebagian besar karyawan mengatakan bawa mereka tidak merasa terbebani dengan apa yang mereka lakukan di pabrik dengan alasan karena sudah terbiasa dengan beban kerja yang dia hadapi setiap harinya, tetapi ada juga karyawan/buruh mengatakan bahwa mereka terbebani karena disana sistem shift jika mereka dapat shift pagi atau shift 1 mulai dari 08.00 sampai dengan 03.00 dan berlanjut ke shift 2 dengan karayawan/buruh yang berbeda tetapi karyawan/buruh berhalangan untuk masuk ke shift tersebut sehingga meminta tolong kepada karyawan/buruh sebelumnya untuk mengisi shift tersebut. Itulah yang dinamakan beban kerja tambahan yang dapat mengakibatkan gangguan kesehatan kerja karena jam kerja yang mereka lakukan melebihi jam kerja yang ditetapkan.

4. Hubungan kelelahan kerja dengan gangguan kesehatan kerja

Kelelahan akibat kerja adalah suatu kondisi fisiologis berkurangnya kemampuan mental atau kemampuan fisik akibat kehilangan waktu tidur, 
Jurnal Sulolipu : Media Komunikasi Sivitas Akademika dan Masyarakat

Vol. 19 No.2 2019

e-issn : 2622-6960, p-issn : 0854-624X

lamanya waktu terjaga dan beban kerja yang berlebih yang dapat mengganggu kemampuan dalam menjalankan keamanan dan keselamatan selama proses operasional dilaksanakan. Berdasarkan tabel 5.9 hasil analisis bivariat dengan menggunakan uji chi square diperoleh nilai $p$ value $0,000<\alpha$ $(0,05)$ maka Ho ditolak dan nilai Ha diterima dengan kesimpulan bahwa ada hubungan yang bermakna antara kelelahan kerja dengan gangguan kesehatan kerja hal ini disebabkan karena sebagian besar kayawan merasakan lelah dalam melakukan pekerjaan.

\section{KESIMPULAN}

Berdasarkan hasil penelitian yang dilakukan di PT. Semen Tonasa Kabupaten Pangkep Tahun 2019, maka dapat disimpulkan sebagai berikut :

1. Ada hubungan antara penyuluhan $\mathrm{K} 3$, beban kerja dan kelelahan kerja dengan gangguan kesehatan kerja di pabrik II,III dan IV PT. Semen Tonasa Kabupaten Pangkep.

2. Tidak ada hubungan antara penggunaan alat pelindung diri (APD) dengan gangguan kesehatan kerja di pabrik II,III dan IV PT. Semen Tonasa Kabupaten Pangkep.

\section{SARAN}

1. Bagi Perusahaan PT. Semen Tonasa Kabupaten Pangkep bagian Produksi khususnya Diklat perlu adanya penyuluhan intensif bagi seluruh karyawan maupun buruh kerja agar mereka lebih mengetahui apa itu Keselamatan Dan Kesehatan Kerja

2. Bagi Perusahaan PT. Semen Tonasa Kabupaten Pangkep bagian Produksi khususnya Kantor K3 agar menambah atau melengkapi Alat Pelindung Diri (APD) terutama ear plug dan masker supaya setiap karyawan atau buruh memiliki APD tersebut.

3. Bagi Perusahaan PT. Semen Tonasa Kabupaten Pangkep khususnya bagian pabrik agar lebih tegas untuk memberikan sanksi kepada karyawan/buruh yang ingin bertukar shift karena dapat berdampak pada kelelahan kerja dan menambah beban kerja yang telah ditentukan yaitu 8 jam kerja.

\section{DAFTAR PUSTAKA}

Permendagri. (2008). Peraturan Menteri Dalam Negeri Nomor 12/2008 tentang Pedoman Analisis Beban Kerja Di Lingkungan Departemen Dalam Negeri dan Pemerintah Daerah. https://jdih.surabaya.go.id Di akses pada 20 Desember 2018.

Waruwu. (2016). Analisis Faktor Kesehatan dan Keselamatan Kerja (K3) Yang Signifikan Mempengaruhi Kecelakaan Kerja Pada Proyek Pembangunan Apartement Student Castle. https://journal.uad.ac.id. Di akses pada 25 Desember 2018.

Buntarto. (2015). Panduan Praktis Keselamatan dan Kesehatan Kerja Untuk Industri .Yogyakarta: Pustaka Baru Press.

Abdul Muhid, Analisis Statistik SPSS for Windows: Cara Praktis Melakukan Analisis Statistik, Surabaya: CV Duta Aksara, 2010

.Hadiningrum, K. (2003). Keselamatan dan Kesehatan Kerja. Bandung: Politeknik Negeri Bandung.Jamsostek (2013). http://www.jamsostek.co.id/content/news.php?id=3956. Di akses pada 20 Desember 2018

KEP-463/MEN, K. B. (1993). Pola Gerakan Nasional Membudayakan Keselamatan dan Kesehatan Kerja. https://jdih.kemnaker.go.id Di akses pada 25 Desember 2018

RI, D. K. (2009). Undang-undang Republik Indonesia Nomor 36. Jakarta: KeSmenterian Kesehatan RI. https://www.depkes.go.id Di akses pada 20 Desember 2018

A.M. Sugeng Budiono. 2003. Bunga Rampai Hiperkes dan Kesehatan Kerja. Semarang: Badan Penerbit UNDIP 
Jurnal Sulolipu : Media Komunikasi Sivitas Akademika dan Masyarakat

Vol. 19 No.2 2019

e-issn : 2622-6960, p-issn : 0854-624X

International Labour Organization, (1989). Buku Pedoman Pencegahan Kecelakaan. Jakarta: Pustaka Binaman Pressindo.

Jamsostek (2013). http://www.jamsostek.co.id/content/news.php?id=3956. Di akses pada 20 Desember 2018 